\title{
"GESTÃO DE ÁGUA NA MORADIA DA UNICAMP-CAMPINAS: ESTRATÉGIA PARA GESTÃO DE CONSUMO".
}

\section{Giovana Biasetti*, Carlos Antônio Zuffo.}

\section{Resumo}

Esse projeto de pesquisa visa a implementação de uma política educacional na Moradia Estudantil da Universidade Estadual de Campinas (UNICAMP) com foco em gestão de água e de resíduos sólidos com o objetivo de obter uma conscientização da população e visando uma moradia mais sustentável, servindo de exemplo para as demais unidades da universidade.

\section{Palavras-chave:}

Gestão de Resíduos Sólidos, Política Educacional, Gestão da Água, Prevenção.

\section{Introdução}

$\mathrm{Na}$ moradia estudantil, encontramos grandes problemas em relação a gestão de resíduos sólidos pois o descarte é feito de maneira inapropriada, sendo prejudicial pois pode atrair vetores de doenças e os alunos ficam mais expostos ao chorume produzido através desse descarte. Podemos observar na Figura 1 um exemplo de um descarte inapropriado, onde no quadro 1 observamos uma série de resíduos depositados nas ruas da moradia e no quadro 2 , um deposito vazio que poderia ser utilizado para o depósito desses resíduos.

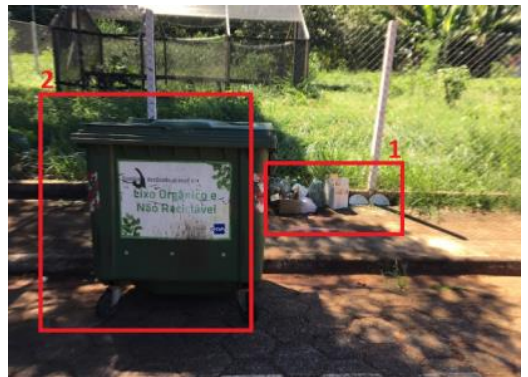

Figura 1. Descarte inapropriado de Resíduos Sólidos na Moradia Estudantil.

Em relação a gestão da água, a moradia está implementando a micromedição em todos os seus blocos e consertando os vazamentos das tubulações do sistema de abastecimento.

Tomando conhecimento sobre isso, este trabalho teve o principal objetivo a implementação de uma política educacional para a gestão da água, visando a redução de custos em relação aos vazamentos e ao consumo de água e, da gestão de resíduos sólidos para proporcionar o descarte correto dos resíduos sólidos.

\section{Resultados e Discussão}

A estrutura da política educacional teve três grandes fatores a serem considerados, sendo eles: econômico, social e ambiental. Cada um deles apresenta uma significativa importante para a conscientização integral da implementação do projeto. Ao decorrer do projeto, foram realizadas três abordagens de ensino diferentes. Sendo elas:

1.Realização de vídeos educacionais que foram exibidos em páginas online para os alunos da moradia, separados pelos dois temas principais sendo eles: gestão geral da água e gestão dos resíduos sólidos.

2.Realização de folders educacionais distribuídos por toda a comunidade estudantil com orientações mais diretas para o melhor manejo do descarte de resíduos sólidos e gestão da água. A distribuição deles segue em negociação com a Secretaria de Vivência nos Campi.

3. Seguimento do projeto de pesquisa e realização de um workshop sobre a gestão de resíduos sólidos no segundo semestre do ano de 2019, auxiliando o futuro bolsista que cuidará da gestão na moradia.

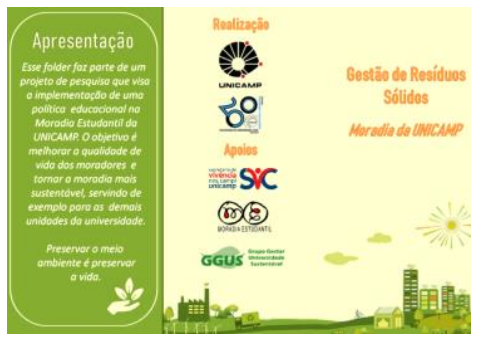

Figura 2. Parte do folder da Gestão de Resíduos Sólidos da moradia desenvolvido durante a pesquisa.

\section{Conclusões}

Políticas educacionais são de suma importância para diversas áreas de estudo, sendo um indicador para o crescimento socioeconômico do país pois a melhoria da educação proporciona oportunidades igualitárias em nossa sociedade. $\mathrm{Na}$ esfera da universidade, a elaboração da política educacional para a gestão da água e dos resíduos sólidos proporcionou uma melhor dimensão dos assuntos para a população da moradia e, uma melhoria a longo prazo na qualidade de vida da população.

\section{Agradecimentos}

Agradeço ao meu professor orientador, Carlos Antônio Zuffo que me acompanhou durante toda a pesquisa. Agradeço a Maria Das Graças F. A. Veredas pelo apoio durante a elaboração dos folders

Agradeço a Paulo Humberto Fozatti, por me ajudar com as questões administrativas na Moradia Estudantil.

E por fim, agradeço ao CNPq e PIBIC pela oportunidade de desenvolver a pesquisa.

ZUFFO, Carlos Antônio e Mônica Soares Resio. Gerenciamento de Recursos Hídricos - Conceituação e Contextualização: Estudo de caso sobre o Sistema Cantareira. Elsevier. 2016

BORTOLETO, Ana Paula. Waste Prevention Policy And Behaviour: New Approaches To Reducing Waste Generation And Its Environmental Impacts. TAYLOR \& FRANCIS LTD, 2014.

DE CONTO, S. M. Gestão de resíduos em universidades. Caxias do Sul, RS EDUCS, 2010. 